\title{
Optimizing a multi-echelon supply chain network flow using nonlinear fuzzy multi-objective integer programming: Genetic algorithm approach
}

\author{
Hessam Zandhessami ${ }^{\mathrm{a}}$, Mehrzad Kashi Zonozi ${ }^{\mathrm{b}}$, and Mohammad Ali Afshari ${ }^{{ }^{*}}$
}

${ }^{a}$ Industrial Management Department, Management and Accounting Faculty, Iran Azad University, Qazvin branch, Qazvin, Iran

${ }^{b}$ Department of Computer Engineering \& Information Technology, Amirkabir University of Technology, Tehran, Iran

${ }^{c}$ Kar University of Qazvin, Qazvin, Iran

A R T I C L E I N F O A B T RAC T

Article history:

Received March 19, 2012

Received in Revised form

June, 20, 2012

Accepted 22 June 2012

Available online

June 242012

Keywords:

Supply chain management

Supply chain network

Genetic algorithm

Multi echelon

Fuzzy theory

\begin{abstract}
The aim of this paper is to present mathematical models optimizing all materials flows in supply chain. In this research a fuzzy multi-objective nonlinear mixed- integer programming model with piecewise linear membership function is applied to design a multi echelon supply chain network (SCN) by considering total transportation costs and capacities of all echelons with fuzzy objectives. The model that is proposed in this study has 4 fuzzy functions. The first function is minimizing the total transportation costs between all echelons (suppliers, factories, distribution centers (DCs) and customers). The second one is minimizing holding and ordering cost on DCs. The third objective is minimizing the unnecessary and unused capacity of factories and DCs via decreasing variance of transported amounts between echelons. The forth is minimizing the number of total vehicles that ship the materials and products along with SCN. For solving such a problem, as nodes increases in SCN, the traditional method does not have ability to solve large scale problem. So, we applied a Meta heuristic method called Genetic Algorithm. The numerical example is real world applied and compared the results with each other demonstrate the feasibility of applying the proposed model to given problem, and also its advantages are discussed.
\end{abstract}

\section{Introduction}

A supply chain is a set of a network of facilities and distribution options that performs the functions of procurement of materials, transformation of these materials into intermediate and finished products, and the distribution of these finished products to customers. Supply chains also exist in both service and manufacturing organizations. Realistic supply chains have multiple finished products with shared components, facilities and capacities (Ermis et al., 2004; Falcone, 2008). A supply chain is a network of organizations that are involved, through upstream and downstream linkages, in various processes and activities that produce value in the form of products and services delivered to the ultimate consumer (Verma \& Seth, 2011). 
As the economy is changing, as competitions become more global it is no longer company vs. company but supply chain vs. supply chain. Properly implemented, supply chain management (SCM) can positively influence many functions and outcomes of the organization including product quality, customer responsiveness and resultant satisfaction, manufacturing cost control, product and market flexibility, and macro performance outcomes including market share and profitability (Meier et al., 2004). In recent years, companies have faced increasing challenges and conflicts in their abilities to detect and to manage labor and employment conditions and the environmental footprint at different tiers of their supply chains (Van Opijnen \& Oldenziel, 2011). In today's global market, if an enterprise wish to succeed in a business environment, it must manage and design its entire supply chain network (SCN). This is obvious that the traditional and usual SCN methods are not sufficient to satisfy conscious customers anymore. To overcome aforementioned problem, enterprises must handle integrated manufacturing and distribution processes together and present alternative options to customers via strong relationships with the suppliers (Paksoy, 2005). It should be noted that supply chain management has traditionally been viewed as a process wherein raw materials are converted into final products, then delivered to the end-consumer (Fortes, 2009). This process is involving extraction and exploitation of the natural resources (Srivastava, 2007). SCM is the integration of key business processes across the supply chain for the purpose of creating value for customers and stakeholders (Lambert, 2008).

The concept of SCM, nowadays, is very important for every organization. This paper presents a decision support system (DSS) mechanism for managers to make appropriate decision on the amount of production as well as the time schedule for ordering in uncertain environment. As it is clear, the world of today has its own complexity and ambiguity. Therefore, it is necessary to overcome to such a critical problem. For overcoming, the paper uses fuzzy sets theory to reduce ambiguity and uncertainty of our environment.

In this study, we develop a mathematical model to optimize the materials flows in supply chain. This model introduces 4 fuzzy functions, which minimizes total costs between suppliers and distribution centers (DCs). The aim of this paper is to provide near-optimal solutions by employing the genetic algorithm (GA) to proposed model. In this study, the model is developed based Paksoy et al. (2010). The rest of this study is coming as below: first, literature review is conducted and we take a look to previous works on SCM concept. Then the proposed model of this paper presented, and for solving the problem, GA algorithm is applied. At the end, the results are compared with each other.

\section{Literature Review}

There are literally tremendous efforts accomplished to establish an appropriate supply chain in order to increase the efficiency and reduce the associated expenditures. To cope with the complicated problem of supply chain, researchers have used mathematical programming or heuristics algorithm to solve such problems. The challenge in global SCM is the development of decision-making frameworks, which accommodate diverse concerns of multiple entities across the supply chain. Considerable efforts have been expended in developing decision models for SC problems (Narasimhan \& Mahapatra, 2004). Melachrinoudis et al. (2000) applied multi objective and integer programming for two-echelon factory/warehousing facility to solve the problem. Ross (2000) implemented performance-based strategic resource allocation to solve the supply chain network design. Syam, (2002) used meta heuristic method called simulated annealing and Lagrangian relaxation in supply chain network environment of multiple echelons to minimize the costs. Schwarz (1973) applied one-warehouse N-retailer inventory model. Muckstadt and Roundy (1987) evaluated multi-item, one-warehouse, multi-retailer in a distribution system. Cheshmberah et al. (2011) proposed a mathematical model to optimize single-commodity distribution in chain stores network. Yang and Wee (2000) proposed a model for buyer and vendor by differential equations. Banerjee (1986) for the first time, present the two-echelon inventory model for vender and buyer. Hill (1999) presented a production and inventory model with integration as a whole. Lau and Lau (2001) 
proposed a two-echelon problem where the retailer has better market information than the manufacturer. Pasternack (2001) applied a single inventory problem vendor (retailer) has limited funds to purchase items to sell.

The issues of how to simultaneously integrate manufacturing and distribution systems in a supply chain with multi objectives have attracted considerable interest from both practitioners and academics (Liang \& Cheng, 2009) respectively. Cohen and Lee (1989) proposed a deterministic, mixed integer, non-linear programming with economic order quantity technique to develop a global supply chain plan. Output of the model provides global resource deployment policy for the factories, distribution centers and customer zones. Paksoy et al. (2010) applied fuzzy nonlinear multi-objective mathematical model for supply chain network.

$\mathrm{Hu}$ and Fang (1999) solved the problem of fuzzy inequalities linear membership function by implementing the concepts of constraint surrogating and maximum entropy. Vasant et al. (2005) proposed a new fuzzy linear programming based methodology applying modified S-curve membership function. Liang (2006) developed an interactive fuzzy multi-objective linear programming method for solving the fuzzy multi objective transportation problems with piecewise linear membership function. Peidro et al. (2007) proposed a new mathematical programming model for supply chain planning under supply, process and demand uncertainty. Chang (2007) proposed a new idea of how to formulate the binary piecewise linear membership function. Alves and Climaco (2007) reviewed interactive methods for multi objective integer and mixed integer programming. Liang (2008) developed a fuzzy multi-objective linear programming model with piecewise linear membership function to solve integrated multi-product and multi-time period production/distribution planning decisions problems with fuzzy objectives. Liang and Cheng (2009) represented fuzzy sets to multi-objective manufacturing/distribution planning decision problems with multi-product and multitime period in supply chains by considering time value of money for each of the operating categories. Peidro et al. (2009) proposed a new mathematical programming model for supply chain planning under supply, process and demand uncertainty. The model has been formulated as a fuzzy mixed integer linear programming model where data are ill-known and modeled by triangular fuzzy numbers. Cao et al. (2010) developed stochastic chance constrained mixed-integer nonlinear programming models to solve the refinery short-term crude oil scheduling problem. Zandhessami et al. (2011) proposed a hybrid ANP and fuzzy goal programming to select the best supplier.

\section{Mathematical model and notations}

In this paper, a fuzzy multi-objective nonlinear mathematical model is proposed for 3 echelons to optimize the supply chain material flows. This research determines the supplier, manufacturer and DC, to design the best supply chain network. The assumptions of proposed model are:

1- Amount of customers and suppliers and also their demand is known.

2- Amount of factories and DCs and their maximum capacities are fuzzy.

3- Customers are serviced at least from a single DC.

The decisions variables of model are coming as follow:

$f_{k j} \quad$ Quantity of the product transformed from $k^{\text {th }}$ factory to $j^{\text {th }} \mathrm{DC}$

$b_{s k} \quad$ Quantity of raw material transformed from $s^{\text {th }}$ supplies to $k^{\text {th }}$ factory

$q_{j i} \quad$ Quantity of the product transformed from DC $j$ to $i^{\text {th }}$ customer

$\eta_{s k} \quad$ Quantity of expected vehicles needs to ship the material from $s^{\text {th }}$ supplier to $k^{\text {th }}$ 
$\eta_{k j} \quad$ Quantity of expected vehicles needs to ship the product from $k^{\text {th }}$ factory to $j^{\text {th }} \mathrm{DC}$

$\eta_{j i} \quad$ Quantity of expected vehicles needs to ship the product from $j^{\text {th }}$ DC to $i^{\text {th }}$ customer

$y_{j i} \quad 1$, if $j^{\text {th }}$ DC is serving customer $i$

0 , otherwise

Parameters of model are:

\begin{tabular}{ll}
\hline$\tilde{D}_{k}$ & Fuzzy capacity of $k^{\text {th }}$ factory \\
$\tilde{S u p}_{s}$ & Fuzzy capacity of $s^{\text {th }}$ supplier for raw material \\
$\tilde{W}_{j}$ & Fuzzy distribution capacity of $j^{\text {th }} \mathrm{DC}$ \\
$d_{i}$ & Demand for the product at $i^{\text {th }}$ customer \\
$C_{j i}$ & Unit transportation cost for the product from $j^{\text {th }}$ DC to $i^{\text {th }}$ customer \\
$a_{k j}$ & Unit transportation cost for the product from $k^{\text {th }}$ factory to $j^{\text {th }}$ DC \\
$t_{s k}$ & Unit transportation and purchasing cost for the raw material from $s^{\text {th }}$ supplier to $k^{\text {th }}$ factory \\
$C_{h}$ & Holding cost per year at $j^{\text {th }}$ DC \\
$\mathrm{s}$ & Ordering cost to $k^{\text {th }}$ factory from each of DCs \\
$\phi_{s}$ & Volume of material at $s^{\text {th }}$ supplier \\
$W_{s}$ & Weight of material at $s^{\text {th }}$ supplier \\
$\phi_{k}$ & Volume of product at $k^{\text {th }}$ factory \\
$W_{k}:$ & $\quad$ Weight of product at $k^{\text {th }}$ factory \\
$\omega_{v}$ & Volume capacity of vehicle. \\
$\omega_{w}$ & Weight capacity of vehicle. \\
\hline
\end{tabular}

- $\tilde{D}_{k}$ fuzzy capacity of $k^{\text {th }}$ factory

- Sup $_{s}$ the fuzzy capacity of $s^{\text {th }}$ supplier for raw material

- $\tilde{W}_{i}$ fuzzy distribution capacity of $j^{\text {th }} \mathrm{DC}$

- $d_{i}$ demand for the product at $i^{\text {th }}$ customer

- $C_{j i}$ unit transportation cost for the product from $j^{\text {th }} D C$ to $i^{\text {th }}$ customer

- $a_{k j}$ unit transportation cost for the product from $k^{\text {th }}$ factory to $j^{\text {th }} \mathrm{DC}$

- $t_{\text {sk }}$ unit transportation and purchasing cost for the raw material from $s^{\text {th }}$ supplier to $k^{\text {th }}$ factory

- $C_{h}$ holding cost per year at $j^{\text {th }} D C$

- $S$ is ordering cost to $k^{\text {th }}$ factory from each of DCs

- $\phi_{\text {s }}$ Volume of material at $s^{\text {th }}$ supplier

- $W_{s}$ Weight of material at $s^{\text {th }}$ supplier

- $\phi_{k}$ Volume of product at $k^{\text {th }}$ factory

- $W_{k}$ Weight of product at $k^{\text {th }}$ factory 
- $\omega_{v}$ Volume capacity of vehicle

- $\omega_{w}$ Weight capacity of vehicle.

The first function is minimizing all transportation costs. The second function is minimizing the annual holding and ordering cost of products in DCs according to the economic order quantity (EOQ) model. The third one is the equity of the capacity utilization ratio for manufacturers and DCs, and it is measured by mean square error (MSE) of capacity utilization ratios. The smaller value is, the closer the capacity utilization ratio for every manufacturer and DC is, thus ensuring the demand are fairly distributed among the DCs and manufacturers, and so it maximizes the capacity utilization balance.

The last one, minimize the quantity of vehicles that transforming the materials and products along the networks. For simplification, the volume and weight of vehicles are constant.

The proposed model is:

$$
\begin{aligned}
& \min f_{1}=\sum_{s} \sum_{k} t_{s k} \cdot b_{s k}+\sum_{k} \sum_{j} a_{k j} \cdot f_{k j}+\sum_{j} \sum_{i} c_{j i} \cdot q_{j i} \\
& \min f_{2}=\sum_{j}\left[\frac{s \cdot \sum_{k} f_{k j}}{\left.\sqrt{\frac{\sum_{k} 2 \cdot S \cdot f_{k j}}{c_{h}}}+\frac{c_{h \cdot} \cdot \sqrt{\frac{\sum_{k}^{2} 2 \cdot S \cdot f_{k j}}{c_{h}}}}{2}\right]}\right. \\
& \min f_{3}=\sqrt{\frac{\sum_{k}\left[\left(\sum_{j} f_{k j} / D_{k}\right)-\left(\sum_{k} \sum_{j} f_{k j} / \sum_{k} D_{k}\right)\right]^{2}}{\sum k}}+\sqrt{\frac{\sum_{j}\left[\left(\sum_{i} q_{j i} / W_{j}\right)-\left(\sum_{j} \sum_{i} q_{j i} / \sum_{i} W_{i}\right)\right]^{2}}{\sum_{j}}} \\
& \min \left(f_{4}\right)=\sum_{s} \sum_{k} t_{s k} \cdot \eta_{s k}+\sum_{k} \sum_{j} \boldsymbol{a}_{k j} \cdot \eta_{k j}+\sum_{j} \sum_{i} C_{j i} \eta_{j i}
\end{aligned}
$$

subject to

$$
\begin{array}{ll}
\sum_{j} y_{j i}=1 & \forall i \\
q_{j i}=d_{i} \cdot y_{j i} & \forall i, j \\
\sum_{i} d_{i} \cdot y_{j i} \leq \tilde{W}_{j} & \forall j \\
\sum_{k} f_{k j}=\sum_{i} q_{j i} & \forall j \\
\sum_{k} b_{s k} \leq \tilde{S u p}_{s} & \forall s \\
\sum_{j} f_{k j} \leq \sum_{s} b_{s k} & \forall k \\
\sum_{j} f_{k j} \leq \tilde{D}_{k} \quad \forall k & \forall_{s k} \\
\sum_{s} \sum_{k} \eta_{s k}-1 \leq \frac{\sum_{s} \sum_{k} t_{s k} \eta_{s k}}{\omega_{v}}<\sum_{s} \sum_{k} t_{s k} \eta_{s k} & \sum_{s} \sum_{k} t_{s k} \eta_{s k} \\
\sum_{s} \sum_{k} \eta_{s k}-1 \leq \sum_{s} \sum_{k} t_{s k} \eta_{s k} & \forall_{s k} \\
\sum_{k} \sum_{j} t_{k j} \eta_{k j}-1 \leq \frac{\sum_{k} \sum_{j} t_{k j} \eta_{k j}}{\omega_{v}}<\sum_{k} \sum_{j} t_{k j} \eta_{k j} & \forall_{k j} \\
\sum_{k} \sum_{j} t_{k j} \eta_{k j}-1 \leq \frac{\sum_{k} \sum_{j} t_{k j} \eta_{k j}}{\omega_{w}}<\sum_{k} \sum_{j} t_{k j} \eta_{k j} & \forall_{k j}
\end{array}
$$




$$
\begin{array}{lc}
\sum_{j} \sum_{i} t_{j i} \eta_{j i}-1 \leq \frac{\sum_{j} \sum_{i} t_{j i} \eta_{j i}}{\omega_{v}}<\sum_{j} \sum_{i} t_{j i} \eta_{j i} & \forall_{j i} \\
\sum_{j} \sum_{i} t_{j i} \eta_{j i}-1 \leq \frac{\sum_{j} \sum_{i} t_{j i} \eta_{j i}}{\omega_{w}}<\sum_{j} \sum_{i} t_{j i} \eta_{j i} & \forall_{j i} \\
y_{j i}=\{0,1\} & \forall_{i, j} \\
b_{s k}, f_{k j}, q_{j i} \geq 0 & \forall_{i, j, k, s} \\
\eta_{j i}, \eta_{k j}, \eta_{s k} \quad \text { [Integer] } \quad \forall_{i, j, k, s} &
\end{array}
$$

Constraint (5) represents that at least 1DC should serve customer, (6) is fuzzy capacity for all DCs, constraints (7) and (8) satisfy customers' demands, constraint (9) represents the fuzzy capacity of suppliers, constraint (10) represents the restriction for raw materials, constraint (11) is fuzzy capacity of manufacturers. Constraints (13) to (17) determine the expected quantity of needed vehicles by function 4. For convenience, to solve the model, we convert the multi objective model to one objective; then applying the analytical hierarchy process (AHP) to give them a weight. So the model could be like:

$\min g_{0}(x)=w_{1} f_{1}+w_{2} f_{2}+w_{3} f_{3}+w_{4} f_{4}$

In fact, we manipulate the weight in all functions.

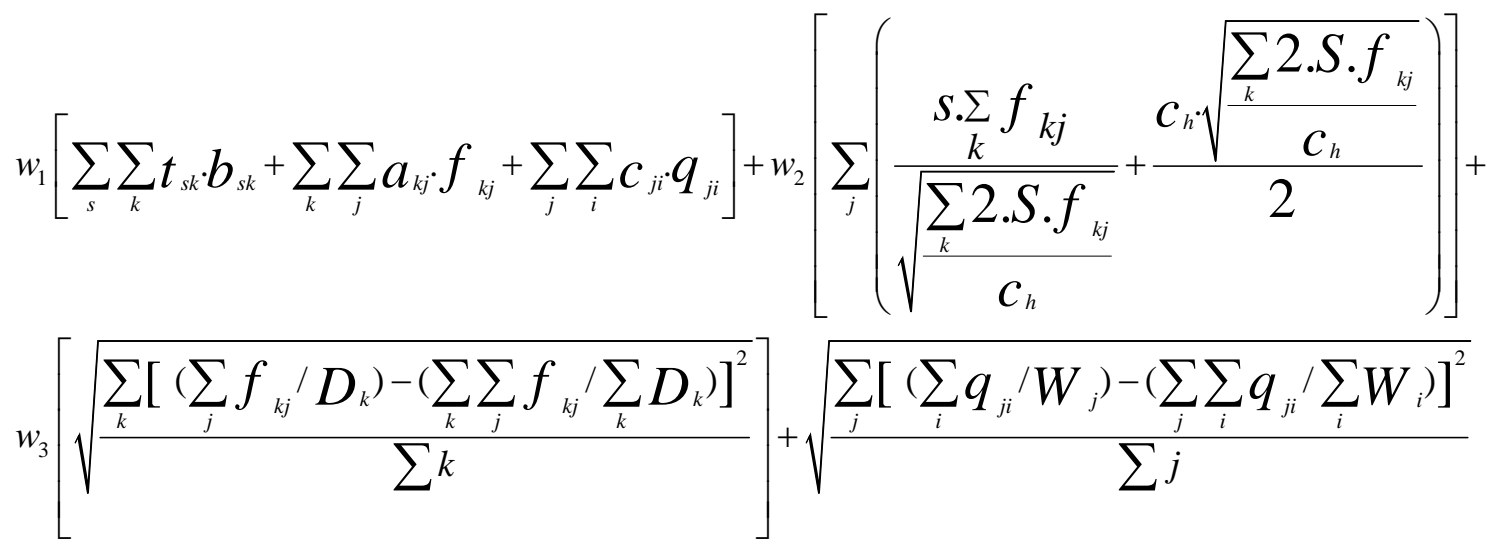

$+W_{4}\left(\sum_{s} \sum_{k} t_{s k} \cdot \eta_{s k}+\sum_{k} \sum_{j} a_{k j} \cdot \eta_{k j}+\sum_{j} \sum_{i} C_{j i} \cdot \eta_{j i}\right)$

\subsection{Model development}

For solving the problem, the model should be converting to crisp model, so we have:

$\min g_{0}(x)$

$$
\begin{aligned}
& (A x) \leq \tilde{b}_{i}, \quad i=1,2, \ldots, m \\
& x \geq 0
\end{aligned}
$$

And by applying Zimmermann’s method (1978), the problem transformed to: 
$\max \alpha$

subject to $\mu_{g_{0}}(x) \geq \alpha, \quad \mu_{i}(x) \geq \alpha, \quad \alpha \in[0,1] \quad x \geq 0$

For Eq (24) S-curve membership function is applied for fuzzy nonlinear objective function and nonincreasing linear membership function is used for fuzzy constraints (Turan et al., 2010). The modified S-curve membership function proposed by Vasant (2005) and has particular value of $\mathrm{B}, \mathrm{C}$ and $\delta$. Modified S-curve membership function is coming as:

$$
\mu(x)= \begin{cases}1, & x<x^{a} \\ 0.999, & x=x^{a} \\ \frac{B}{1+C e^{\delta x},} & x^{a}<x<x^{b} \\ 0.001, & x=x^{b} \\ 0, & x>x^{b}\end{cases}
$$

In this Eq. (25), $\mu$ is the degree of membership function. Vasant(2005) determined the parameters of $\mathrm{B}, \mathrm{C}$ and $\mu$. So they are: as $\mathrm{B}=1, \mathrm{C}=0.001001001$ and $\delta=13.81350956$. Fig. 1 shows the modified S-curve model.

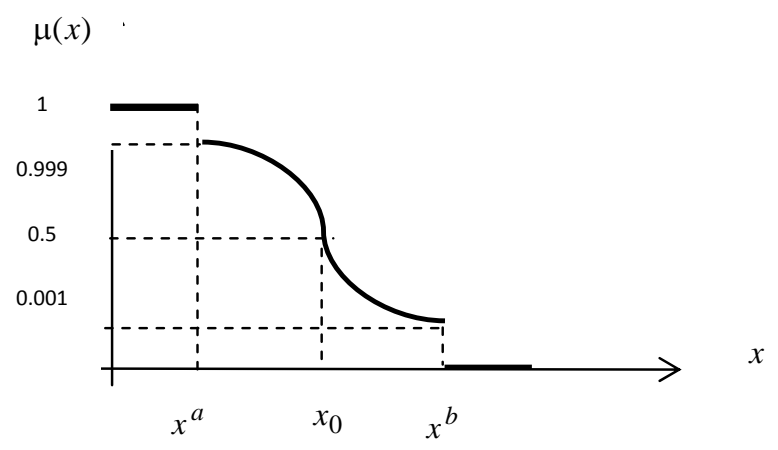

Fig. 1. S-curve modified model

The non-increasing linear membership function is described by Fig. 2 and Eq. (26):

$\mu_{i}(x)=\left\{\begin{array}{l}1, \quad(A x)_{i}<b_{i} \\ 1-\frac{\left[(A x)_{i}-b_{i}\right]}{p_{i}}, \quad b_{i} \leq(A x)_{i} \leq b_{i}+p_{i} \\ 0, \quad(A x)_{i}>b_{i}+p_{i}\end{array}\right.$

$$
\mu_{i}(x)
$$

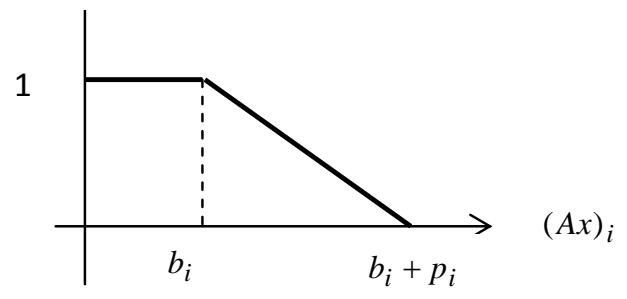

Fig. 2. The membership functions for the fuzzy constraints $(A x)_{i} \leq \tilde{b}_{i} \quad$ (Turan et al., 2010) 


\section{Genetic algorithm (GA)}

GAs is an evolutionary process that implementing "a survival of the fittest" strategy (Rezaei \& Davoodi, 2008). GAs is probabilistic search techniques that their mechanism is based on natural selection. This technique is searching global near-optimal solution of functions and satisfying constraints. For more study of this evolutionary global-search technique, it is suggested to read Davis (1991), Golderberg (1989), Holland (1975) and Michalewicz (1994). GAs has some operators that should be noted in this study. One of the operators is Chromosome. In fact, chromosome is sets of solutions. Fig. 3 shows the schematic structure of chromosome in our study.

\begin{tabular}{|l|l|l|l|l|l|l|}
\hline $\mathrm{Y}_{11}$ & $\mathrm{Y}_{12}$ & $\cdots$ & $\mathrm{Y}_{\mathrm{ji}}$ & $\cdots$ & $\mathrm{Y}_{\mathrm{ji}-1}$ & $\mathrm{Y}_{\mathrm{ji}}$ \\
\hline
\end{tabular}

Fig. 3. Chromosomes consisting binary variables

Fig. 3 shows the binary variables used for the proposed study of this paper. The next one is mutation and crossover. Crossover and mutation are of the proposed GA of this paper are adopted from Michalewicz (1994). In fact crossover mixed information of parent and the new children have a resemblance to each parent. In addition, mutation expands the solution area and ensures that GA achieves global near-optimal solution. Fig. 4 shows the proposed GA used to solve the proposed model.

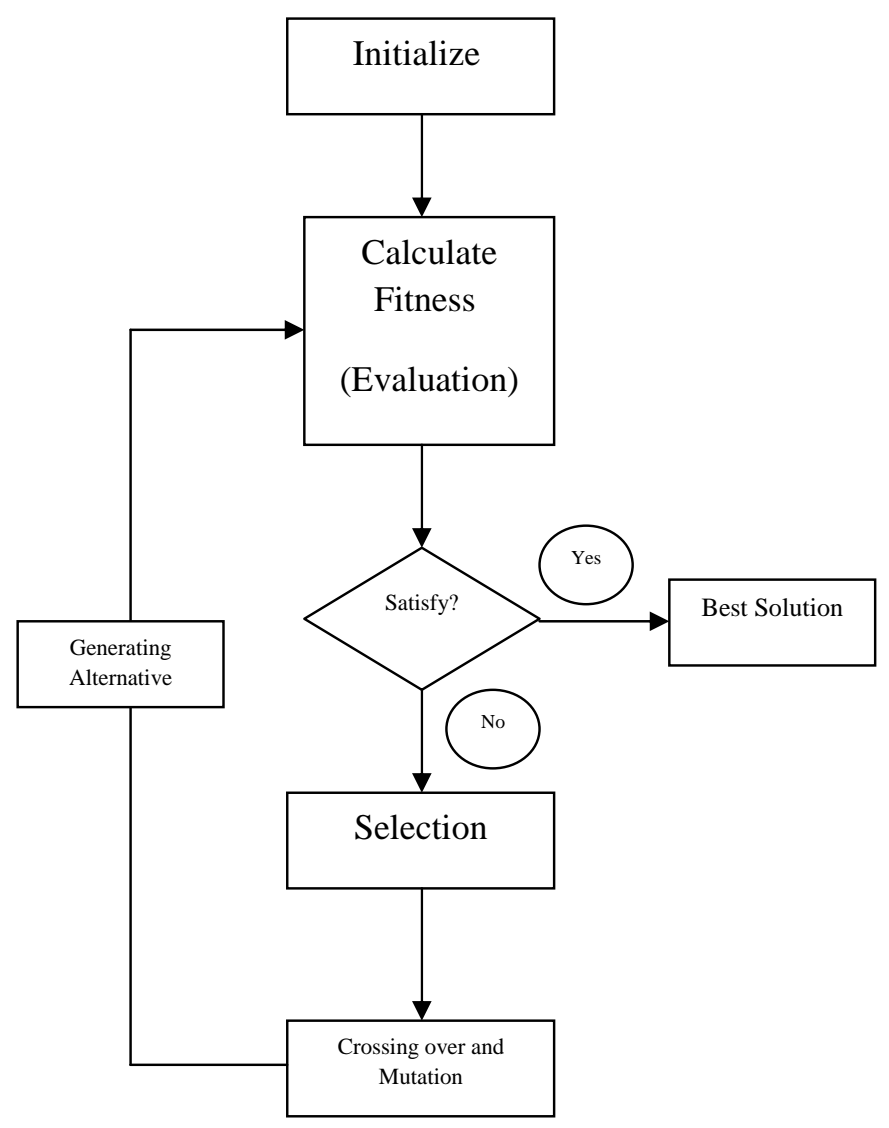

Fig. 4. GA structure (Golderberg, 1989)

Optimization process, in GA, is based on generating sets of chromosome that is called population is started. The population has $\mathrm{N}_{\text {pop }}$ chromosome and could be performed by: $\mathrm{N}_{\text {pop }} \times\left(N_{b i t s} \times N_{\text {var }}\right)$ that they are 0 and 1 matrices. Therefore, we would have: 
pop $=$ round $\left[\right.$ rand $\left(N_{p o p}, N_{b i t s} \times N_{\text {var }}\right)$

For example, in this research, we have 120 variables $\left(\mathrm{N}_{\mathrm{var}}=120\right)$, and for every variables we put 5 bit $\left(\mathrm{N}_{\mathrm{bit}}=5\right)$. Also the population size is $90\left(\mathrm{~N}_{\mathrm{pop}}=90\right)$.

After generating initial population, the fitness function is evaluated. The iterations on this study, was 130 times. Selection has the most important role in GA process. In addition, tournament selection operator is applied to select best chromosome in this study. Two-point crossover is applied in this study because it is determined as the best operator. The Fig. 5 shows the schematic crossover operations in this study.

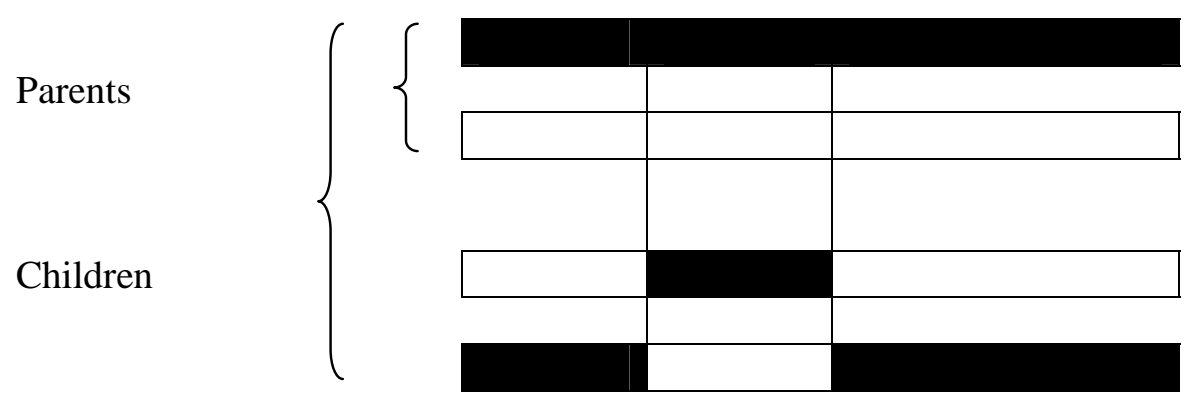

Fig. 5. Tow-point crossover

A mutation is applied generation by generation. It should be noted that mutation expands the feasible space. Rate of mutation was 0.2 in this study. After determining the rate of mutation, we could calculate the amount of chromosome should be mutated. The Eq. (28) shows details of our computations,

number of mutation $=\mu \times\left(N_{\text {pop }}-1\right) \times N_{\text {bit }}$

So in this paper: $0.2 *(90-1) * 5=89$. This means that 89 chromosome should be mutated.

Nmut=ceil $\left(\left(\mathrm{N}_{\mathrm{pop}}-1\right) * \mathrm{~N}_{\mathrm{bit}}{ }^{*} \mu\right) ; \quad$ \%number of mutation
Nrow=ceil (rand $\left.(1, \mu) *\left(\mathrm{~N}_{\mathrm{pop}}-1\right)\right)+1 ; \%$ the row that mutation is occurred
Ncol=ceil (rand $\left.(1, \mu) * \mathrm{~N}_{\mathrm{bit}}\right) ; \quad \%$ the bit that mutation is occurred
Pop (nrow,mcol)=abs (pop (nrow,mcol) -1$) ;$

Fig. 6. Pseudo code for mutation

Offspring: $\quad 0110100011010110011$

Offspring: $\quad 0110100000010110011$

Fig. 7. Mutation occurrence

There are some strategies to terminate the algorithm. One of them is specified maximum generations. The other one is convergence criteria. In this paper, we employed maximum generations as termination strategy. 


\section{Numerical example}

In this part, we illustrate the numerical example of real-world SCN. An automobile part maker in Iran is conducted in this study. We have 6 suppliers, 4 factories, 3 DCs and 5 customers. Table 1 demonstrates the data set of this research.

Table 1

Fuzzy data set for this paper $\left(b_{i}, b_{i}+p_{i}\right)$

\begin{tabular}{lllll}
\hline & Suppliers & Manufacturers & DCs & Customers \\
\hline 1 & $(4300,4340)$ & $(5300,6000)$ & $(7800,9000)$ & 4000 \\
2 & $(4310,5400)$ & $(6000,6400)$ & $(6700,8700)$ & 4000 \\
3 & $(5400,6000)$ & $(5000,7000)$ & $(6000,6590)$ & 4000 \\
4 & $(3600,5600)$ & $(4900,5700)$ & -- & 4000 \\
5 & $(4000,4500)$ & & & 4000 \\
& $6(3800,4300)$ & ---------- & ---------- & \\
\hline
\end{tabular}

In this study, we are comparing the results of GA and fuzzy multi objective problem. Analytical hierarchy process (AHP) is applied to give the weight to functions. In Table 2 pairewised comparison is performed,

\section{Table 2}

Pairewised comparison (AHP)

\begin{tabular}{|c|c|c|c|c|}
\hline & $f_{1}$ & $f_{2}$ & $f_{3}$ & $f_{4}$ \\
\hline$f_{1}$ & 1 & 2 & 3 & 6 \\
\hline$f_{2}$ & $1 / 2$ & 1 & 2 & 3 \\
\hline$f_{3}$ & $1 / 3$ & $1 / 2$ & 1 & 5 \\
\hline$f_{4}$ & $1 / 6$ & $1 / 3$ & $1 / 5$ & 1 \\
\hline Sum & 2 & 3.83 & 6.2 & 15 \\
\hline
\end{tabular}

At last, the weight for functions coming as: $W_{1}=0.477, W_{2}=0.259, W_{3}=0.198$ and $W_{4}=0.068$. For proposed S-curve membership we have:

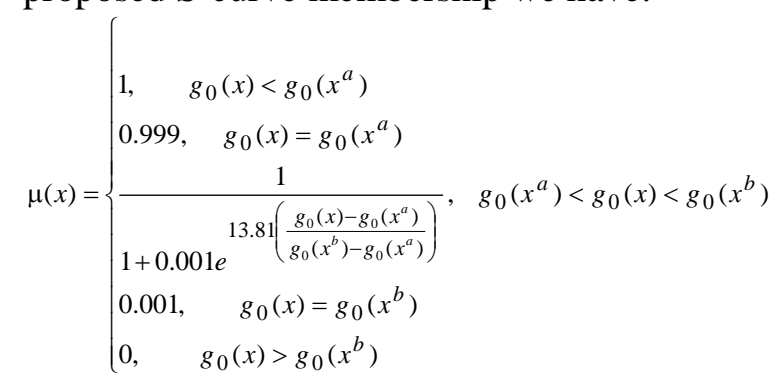

$g_{0}\left(x^{a}\right)=14320.6, g_{0}\left(x^{b}\right)=21340.5$ which is obtained from maximizing and minimizing $\left(\mathrm{g}_{0}\right)$.

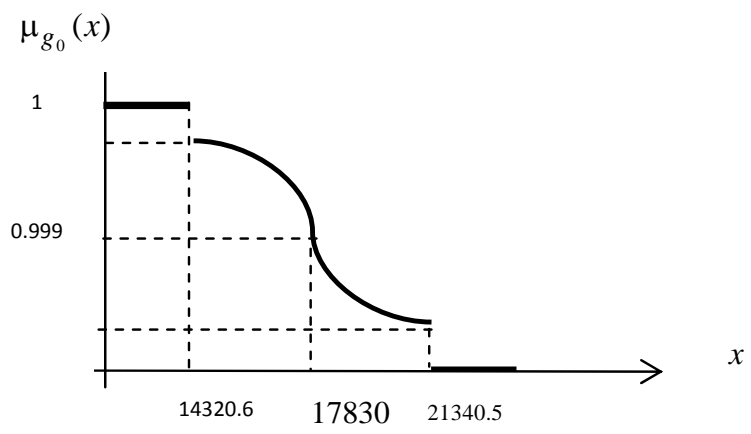

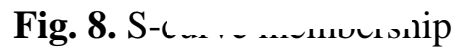


Table 3 to 5 demonstrate the transportation cost between echelons.

Table 3

Unit shipment costs (\$)

\begin{tabular}{lllllll}
\hline & \multicolumn{7}{c}{ Suppliers } \\
\hline Manufacturers & 1 & 2 & 3 & 4 & 5 & 6 \\
\hline 1 & 3.5 & 5 & 3.4 & 6.4 & 3.5 & 4 \\
2 & 2.4 & 3 & 2 & 5 & 1.5 & 7 \\
3 & 4 & 4.5 & 6 & 3.8 & 7.4 & 3.2 \\
4 & 1 & 11 & 3.6 & 5 & 5.3 & 3 \\
\hline
\end{tabular}

Table 4

Unit shipment costs (\$)

\begin{tabular}{lllll}
\hline & \multicolumn{4}{l}{ Manufacturers } \\
\hline DCs & 1 & 2 & 3 & 4 \\
\hline 1 & 3 & 2.4 & 1.1 & 2 \\
2 & 2.3 & 1.2 & 3 & 5 \\
3 & 1.3 & 2 & 1 & 3 \\
\hline
\end{tabular}

Table 5

Unit shipment costs (\$)

\begin{tabular}{|c|c|c|c|}
\hline & \multicolumn{3}{|c|}{ DCs } \\
\hline Customers & 1 & 2 & 3 \\
\hline 1 & 2 & 1.3 & 4 \\
\hline 2 & 0.7 & 1.3 & 5.4 \\
\hline 3 & 1.4 & 2.5 & 3 \\
\hline 4 & 1 & 3 & 3.5 \\
\hline 5 & 2 & 4 & 1 \\
\hline
\end{tabular}

Tables 6 demonstrates details of the results of the implementation of our GA method for the proposed method of this paper.

Table 6

The results obtained by LINGO and MATLAB 7.8 packages program

\begin{tabular}{ll|ll}
\hline GA Fuzzy Problem & & Fuzzy Problem & \\
\hline Decision variable & Value & Decision variable & Value \\
\hline $\mathrm{b}_{1,1}$ & 2190 & $\mathrm{~b}_{1,3}$ & 1800 \\
$\mathrm{~b}_{4,3}$ & 4320 & $\mathrm{~b}_{2,1}$ & 3200 \\
$\mathrm{~B}_{6,2}$ & 3690 & $\mathrm{~b}_{2,2}$ & 2900 \\
$\mathrm{~b}_{5,3}$ & 1056 & $\mathrm{~b}_{3,2}$ & 400 \\
$\mathrm{f}_{1,1}$ & 3100 & $\mathrm{~b}_{4,1}$ & 1600 \\
$\mathrm{f}_{3,3}$ & 5000 & $\mathrm{~b}_{5,3}$ & 2900 \\
$\mathrm{q}_{1,2}$ & 2000 & $\mathrm{f}_{1,2}$ & 2800 \\
$\mathrm{q}_{1,3}$ & 2901 & $\mathrm{f}_{2,1}$ & 3100 \\
$\mathrm{q}_{3,1}$ & $\mathrm{f}_{3,2}$ & 4000 \\
$\mathrm{q}_{3,4}$ & 3100 & $\mathrm{f}_{3,3}$ & 3100 \\
$\mathrm{y}_{1,2}$ & 3100 & $\mathrm{q}_{1,4}$ & 3100 \\
$\mathrm{y}_{1,3}$ & 1 & $\mathrm{q}_{2,2}$ & 3100 \\
$\mathrm{y}_{3,1}$ & 1 & $\mathrm{q}_{2,3}$ & 3100 \\
$\mathrm{y}_{3,4}$ & 1 & $\mathrm{q}_{3,1}$ & 3100 \\
& 1 & $\mathrm{y}_{1,4}$ & 1 \\
& & $\mathrm{y}_{2,2}$ & 1 \\
& & $\mathrm{y}_{2,3}$ & 1 \\
\hline Objective & & $\mathrm{y}_{3,1}$ & 1 \\
\hline$f_{1}$ & & Objective & 39800 \\
$f_{2}$ & 30120 & $f_{1}$ & 1600 \\
$f_{3}$ & 1100 & $f_{2}$ & 0.58 \\
$f_{4}$ & 0.27 & $f_{3}$ & 25 \\
Time & 21 & $f_{4}$ & 4 min \\
\hline & 2 Tin & & \\
\hline
\end{tabular}


For first echelon 12 vehicles, the second echelon 10 vehicles and third echelon 3 vehicles needed (fuzzy model). In addition, for GA fuzzy model we have 9, 8 and 4 vehicles for every echelon respectively.

\section{Conclusion}

In this study, we presented and developed a nonlinear fuzzy mixed integer programming. The proposed model of this paper considered four functions for minimization of all costs and maximization of the utility of capacity in given network. The major assumptions were that, suppliers, DCs and factories are known, and each customer is served at least by one DC. We have explained that, as number of nodes increases in the network, traditional methods could not able to achieve efficient results in an acceptable amount of time. Therefore, we employed GA to obtain the results and the proposed fuzzy GA model has shown to have better solutions than fuzzy model. The results show that how much materials and products should be ordered and transported. In addition, the proposed model reduced $13 \%$ of total costs in network for the company.

As a future study, it is recommended to consider uncertainty for costs and expand the proposed model of this paper for more realistic cases. In addition, other Meta heuristic methods like Artificial Bee Colony (ABC), Simulated Annealing (SA) and Ant Colony (AN) are suggested to be applied for solving the problems.

\section{References}

Alves, M.J. \& Climaco, J. (2007). A review of interactive methods for multi objective integer and mixed-integer programming approach. European Journal of Operational Research, 180, 99-115.

Banerjee, A. (1986). A joint economic lot-size model for purchaser and vendor. Decision Sciences, $17,292-311$

Cao, C., Gu, X., \& Xin, Z. (2010). Stochastic chance constrained mixed-integer nonlinear programming models \& the solution approaches for refinery short-term crude oil scheduling problem. Applied Mathematical Modelling, 34(11), 3231-3243.

Chang, C.T. (2007). Binary behavior of fuzzy programming with piecewise linear membership functions. IEEE Transactions on Fuzzy Systems, 15 (3), 342-349.

Chen, L., \& Lee, W. (2004). Multi objective optimization of multi echelon supply chain networks with uncertain product demands \& prices. Computers and Chemical Engineering, 28, 1131-1144.

Cheshmberah, M., Zahedi, M.R., Hadizadeh, A., \& Tofighi, S.M. (2011). A mathematical model for optimum single-commodity distribution in the network of chain stores: a case study of food industry. Management Science Letter, 1(4), 575-582.

Cohen, M.A., \& Lee, H.L. (1989). Resource deployment analysis of global manufacturing and distribution networks. Journal of Manufacturing and Operations Management, 2, 81-104.

Davis, L. (1991). The Handbook of Genetic Algorithms. Van Nostrand Reinhold, New York.

Goldberg, D.E. (1989). Genetic Algorithms in Search, Optimization, \& Machine Learning. AddisonWesley, Reading, MA.

Ermis, M., Sahingoz, O.K. \& Ulengin, F. (2004). Mobile agent based supply chain modeling with neural network controlled services. Proceedings of 4th International ICSC Symposium on Engineering of Intelligent Systems, Island of Madeira Portugal, pp.1-8.

Falcone, M.A., Lopes, H.S., \& dos Santos Coelho, L. (2008), Supply chain optimisation using Evolutionary Algorithms. International Journal of Computer Applications in Technology, 158166.

Fortes, J. (2009). Green Supply Chain Management: A Literature Review. Otago Management Graduate Review, 7, 51-62.

Hill, R.M. (1999). The optimal production \& shipment policy for the single-vendor single-buyer integrated production-inventory model. International Journal of Production Research, 37, 24632475. 
Hu, C.F. \& Fang, S.C. (1999). Solving fuzzy inequalities with piecewise linear membership functions, IEEE Transactions on Fuzzy Systems, 7 (2), 230-235.

Holland, J.H. (1975). Adaptation in Natural \& Artificial Systems. The University of Michigan Press, Ann Arbor, IL.

Lambert, Douglas M. (editor) (2008). Supply Chain Management: Processes, Partnerships, Performance, $3^{\text {rd }}$ Edition, The Hartely Press Inc., USA.

Lau, A., \& Lau, H. (2001). Some two-echelon style-goods inventory models with asymmetric market information. European Journal of Operational Research, 134, $29-42$.

Liang, T.F. (2008). Fuzzy multi-objective production/distribution planning decisions with multiproduct and multi-time period in supply chain. Computers and Industrial Engineering, 55, 676694.

Liang, T.F., \& Cheng, H.W. (2009). Application of fuzzy sets to manufacturing/distribution planning decisions with multi-product and multi-time period in supply chains. Expert Systems with Applications 36, 3367-3377.

Liang, T.F. (2006). Distribution planning decisions using interactive fuzzy multi-objective linear programming. Fuzzy Sets and Systems, 157, 1303-1316.

Meier, R. L., Williams, M. R. \& Singley, R B. (2004), Supply Chain Management: Strategic Factors From The Buyers’ Perspective. Journal of Industrial Technology, 20(2), 1-8.

Melachrinoudis, E. \& Min, H. (2000). The dynamic relocation and phase-out of a hybrid, twoechelon plant/warehousing facility: a multiple objective approach. European Journal of Operational Research, 123(1), 1-15.

Michalewicz, Z. (1994). Genetic Algorithms + Data Structures = Evolution Programs. AI Series, Springer, New York.

Muckstadt, J.A., Roundy, R. O. (1987). Multi-Item, One- Warehouse, Multi-Retailer Distribution Systems. Management Science, 33, 1613-1621.

Narasimhan, R. \& Mahapatra, S. (2004). Decision models in global supply chain management. Industrial Marketing Management, 33, 21-27.

Paksoy, T. (2005). Distribution network design \& optimization in supply chain management: under material requirements constraints a strategic production-distribution model, Journal of Selcuk University Social Sciences Institute 14, 435-454, in Turkish.

Paksoy, T., Pehlivan, N.Y., \& Özceylan, E. (2010). A Fuzzy Multi Objective Mixed Integer Programming Model for Multi Echelon Supply Chain Network Design and Optimization, 3rd Conference on Nonlinear Science and Complexity, July 28-31, Ankara.

Pasternack, B. (2001). The capacitated newsboy problem with revenue sharing. Journal of Applied Mathematics and Decision Sciences, 5, 21-33.

Peidro, D., J. Mula \& Poler, R. (2007). Supply chain planning under uncertainty: a fuzzy linear programming approach. Fuzzy Systems Conference, 2007 FUZZ-IEEE, 2007 IEEE International, pp. 1-6.

Peidro, D., Mula, J., Poler, R., \& Verdegay, J.L. (2009). Fuzzy optimization for supply chain planning under supply, demand and process uncertainities. Fuzzy Sets and Systems 160 (18), 26402657.

Rezaei, J., \& Davoodi, M. (2008). A deterministic, multi-item inventory model with supplier selection and imperfect quality. Applied Mathematical Modelling 32, 2106-2116.

Ross, A. D. (2000). Performance-based strategic resource allocation in supply networks. International Journal of Production Economics, 63(2), 255-266.

Srivastava, S. (2007). Green supply-chain management: A state-of-the-art literature review. International Journal of Management Reviews, 9(1), 53-80.

Schwarz, L.B. (1973). A simple continuous review deterministic one-warehouse N-retailer inventory problem. Management Science, 19, 555-566

Syam, S.S. (2002). A model and methodologies for the location problem with logistical components. Computers \& Operations Research, 29, 1173-1193. 
Van Opijnen, M., \& Oldenziel, J. (2011), Responsible supply chain management: Potential success factors and challenges for addressing prevailing human rights and other CSR issues in supply chains of EU-based companies.

Vasant, P., Nagarajan, R., \& Yacoob, S. (2005). Fuzzy linear programming with vague objective coefficients in an uncertain environment. Journal of the Operational Research Society, 56, 597603.

Verma, A. \&, Nitin, S. (2011). A Conceptual Framework for Supply Chain Competitiveness, International Journal of Human and Social Sciences, 6, 1, 5-10.

Yang, P. C. \& Wee, H. M. (2000). Economic ordering policy of deteriorated item for vendor and buyer: An integrated approach. Production Planning and Control, 11,474-480.

Zandhessam, H., Afshari, M. A., Siahkali, M.J., \& Ayazi, S.A. (2011). A hybrid analytical network process and fuzzy goal programming for supplier selection: A case study of auto part maker. Management Science Letter, 1(4), 583-594

Zimmermann H.J. (1978), Fuzzy programming and linear programming with several objective functions. Fuzzy Sets and Systems, 1, 45-55

\section{Appendix( Membership functions for echelons)}

Non-increasing linear membership function for DC

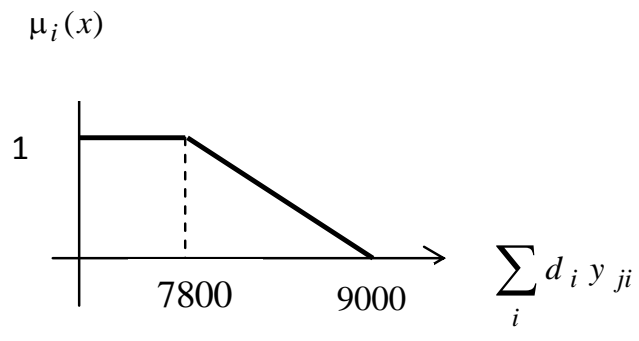

$$
\mu_{i}(x)=\left\{\begin{array}{l}
1, \quad \sum_{i} d_{i} y_{j i}<7800 \\
1-\frac{\left[\sum_{i} d_{i} y_{j i}-7800\right]}{1200}, \quad 7800 \leq \sum_{i} d_{i} y_{j i} \leq 9000 \\
0, \quad \sum_{i} d_{i} y_{j i}>9000
\end{array}\right.
$$

Non-increasing linear membership function for first Manufacturer’s fuzzy capacity



$$
\mu_{i}(x)=\left\{\begin{array}{l}
1, \quad \sum_{j} f_{k j}<5300 \\
1-\frac{\left[\sum_{j} f_{k j}-5300\right]}{700}, \quad 5300 \leq \sum_{j} f_{k j} \leq 6000 \\
0, \quad \sum_{j} f_{k j}>6000
\end{array}\right.
$$

Non-increasing linear membership function for first supplier

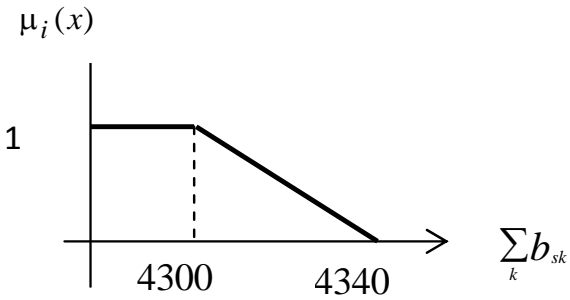

$$
\mu_{i}(x)=\left\{\begin{array}{l}
1, \quad \sum_{k} b_{s k}<4300 \\
1-\frac{\left[\sum_{k} b_{s k}-4300\right]}{40}, \quad 4300 \leq \sum_{k} b_{s k} \leq 4340 \\
0, \quad \sum_{k} b_{s k}>4340
\end{array}\right.
$$

